\title{
Experiências de ruptura de usuários de drogas ${ }^{1}$
}

\author{
Jacqueline Schneider \\ Mestre em Antropologia Social (Universidade Federal de Santa Catarina) \\ Professora do Centro Universitário Católico de Santa Catarina \\ schneider.jac@gmail.com
}

\begin{abstract}
Resumo Este trabalho discute narrativas de usuários de drogas sobre experiências desencadeadoras de intervenção terapêutica a partir de etnografia realizada nas seguintes instituições localizadas na região metropolitana de Curitiba, estado do Paraná, Brasil: Igreja do Santo Daime Céu da Nova Vida, Comunidade Terapêutica Água da Vida e um grupo dos Alcóolicos Anônimos. Através da reconstituição e interpretação das narrativas, indico elementos atuantes no processo de definição de rupturas nas trajetórias de vida, articuladas nas categorias analíticas emergência de eventos críticos e conjuntura de vida. A partir da leitura dessas categorias, sugiro a constituição de perturbação físico-moral na trajetória dos interlocutores. Como uma perspectiva conjunta, sugiro também que os relatos demonstram a formulação de modelos coletivos de avaliação e reelaboração das experiências, pautados pela lógica absenteísta e medicalizante do uso de drogas.
\end{abstract}

Palavras-chave: drogas; experiência; trajetória; ruptura, perturbação.

\section{Apresentação}

$\mathrm{O}$

QUE CONVENCIONAMOS Chamar DE DROGAS, em sociedades como a nossa, são objetos técnicos que podem ser também denominados substâncias psicoativas, pois são capazes de alterar a consciência humana através da atuação sobre o funcionamento neural e o sistema nervoso. A literatura das ciências sociais já investiu significativamente no argumento de que o consumo de drogas é uma prática largamente difundida no espaço e no tempo. Há de fato uma "ubíqua e contínua presença das drogas em cada cultura e uma imensa rede de significados culturais, ritos e práticas de socialização nelas consubstanciadas" (Carneiro, 2005, p. 17). Se essa presença é constante, tanto o conceito "droga" quanto o conceito "vício" são polissêmicos na sociedade contemporânea, constituídos historicamente, adquirindo apenas recentemente a edificação de um paradigma do abuso de drogas (Carneiro, 2005).

$\mathrm{Na}$ nossa sociedade, as drogas se tornaram o reencantamento do mal (Zaluar, 2004), o terror que paira e o pesadelo ocidental (Vargas, 2001). Para essa caracterização e conjuntura estão presentes intensos debates nas esferas jurídica e médica que acabam por definir a pauta política sobre o assunto. Dessa forma, a criminalização e a medicalização do consumo definem a representação do que podemos chamar de fenômeno das drogas (Vargas, 2001). Esses processos se tornaram regimes de relevância densa, atuantes na elaboração das experiências de atores sociais que de alguma forma constituem o contexto das drogas. Em decorrência desse quadro, eventos e experiências se tornam críticos e insustentáveis por se inserirem nesse contexto. Como uma resposta a esses 
eventos, as trajetórias e os itinerários dos usuários de drogas muitas vezes cruzam instituições específicas que se organizam a partir da medicalização do consumo que segue a lógica absenteísta, ou seja, defendem a proibição e a repressão absolutas ao consumo.

Procurando oferecer um modelo de compreensão sobre esses eventos, analiso, neste trabalho, narrativas de usuários de drogas sobre experiências desencadeadoras de intervenção terapêutica. Como uma perspectiva conjunta que se tornou necessária, realizo uma reflexão acerca de modelos pessoais e coletivos de reelaboração das experiências por parte dos sujeitos. Um bom caminho para desnaturalizar representações é procurar compreender como elas são manipuladas em situações de conflito ou de negociação da realidade (Velho, 1974). Dessa forma, também me detenho sobre questões mais básicas de como, por exemplo, experiências pessoais e sociais se transformam em um problema social construído e manipulado por uma rede de atores que determina uma ruptura na trajetória de vida. Ao recuperar as experiências narradas pelas próprias pessoas, enfoco processos que podem desestabilizar definições socialmente hegemônicas.

A etnografia que possibilitou estas reflexões foi realizada nas seguintes instituições localizadas na região da grande Curitiba, no estado do Paraná, Brasil: um grupo de uma associação de anônimos - os Alcoólicos Anônimos (AA); a Igreja do Santo Daime Céu da Nova Vida (ICNV); e o Centro de Recuperação Água da Vida (CRAVI), que se encaixa no modelo de comunidade terapêutica. A escolha desses locais se pautou em acessibilidade, concordância dos dirigentes com a realização da pesquisa e em critérios de variedade dos recursos terapêuticos, procurando enfocar nos sujeitos e nas possíveis diferenças entre os relatos que poderiam emergir a partir de localizações específicas.

Após a negociação com os coordenadores das instituições e a autorização da pesquisa, iniciei o processo de observação participante. Especialmente na ICNV e na CRAVI, partilhei da vida institucional por um período aproximado de três meses e estabeleci uma relação de proximidade com os meus interlocutores que permitiu a realização de uma série de entrevistas. Essa aproximação permitiu que a dinâmica de realização das entrevistas se estabelecesse através da espontaneidade de aproximação. Ou seja, a procura pela entrevista poderia ser realizada por mim ou pelo sujeito a ser entrevistado.

Para "constituir" as narrativas, optei pela técnica da "fala aberta" na realização das entrevistas. Essa técnica objetivou o favorecimento de uma conjun- tura que evitasse uma sobreposição do objeto teórico sobre a agenda de relevâncias dos próprios sujeitos. Favorecer a fala aberta consistiu em oferecer apenas um estímulo à narrativa, condensado na apresentação da proposta da pesquisa, para em seguida solicitar que a pessoa falasse livremente sobre as experiências que as levaram até a instituição terapêutica. Encerrada a fala do sujeito, eu procurava questionar aspectos levantados no diálogo que eu considerasse importante, ou apenas estimular que o interlocutor falasse mais sobre algum tema específico.

No presente trabalho, apresento as instituições terapêuticas e a reconstituição das narrativas de quatro interlocutores registradas nas situações de entrevista, pois acredito que essa seja uma forma adequada de realizar uma "etnografia do particular" (Abu-Lughod, 1991). Ou seja, trata-se de buscar uma narrativa etnográfica que não procure generalizar e homogeneizar idiossincrasias em trajetórias e experiências de interlocutores diferenciados. Opto também por uma reconstituição das narrativas individuais para poder melhor situar as experiências no interior de tramas maiores e assim evitar o impacto de uma descaracterização dos sujeitos e suas trajetórias.

\section{Instituições e narrativas dos sujeitos}

\section{Alcoólicos Anônimos e Jaime}

Os participantes dos Alcoólicos Anônimos se consideram uma irmandade de pessoas que busca resolver o problema comum da "doença do alcoolismo", através do compartilhamento de experiências, em reuniões realizadas geralmente entre uma ou várias vezes por semana. Existem incontáveis grupos de AA em atuação em muitos países e cidades, assim como por toda a região de Curitiba. Minha pesquisa se realizou em um grupo que se reunia na Igreja Bom Jesus, localizada em uma das regiões centrais da cidade de Curitiba, onde tive a oportunidade de entrevistar Jaime.

Nessa entrevista, Jaime conta que começou a beber desde a adolescência: sempre bebia demais, precisando ser carregado. Como ele não tinha muito dinheiro, então o seu alcoolismo ${ }^{3}$ sempre esteve sob controle. Mas aí ele começou a trabalhar, ter seu próprio dinheiro... E aí eu não parei mais! Jaime trabalhou por bastante tempo nos Correios, empresa que lhe proporcionou cinco internações. Contudo, saiu dos

2. Esta técnica foi idealizada em projeto de pesquisa sobre saúde e uso de drogas vinculado ao PPGAS-UFSC e coordenado pelo professor Alberto Groisman.

3. As passagens em itálico são transcrições literais das narrativas dos sujeitos. 
Correios, entrou em um banco, sem conseguir parar em emprego algum. Não tinha dificuldades para arrumar emprego, pois sempre manipulava as situações de entrevista: dizem, né, que todo dependente químico é inteligente. Seu casamento durou muito pouco tempo, tudo por causa do seu alcoolismo. Sua esposa o incentivava a se tratar, mas ele não queria. Não acompanhou o crescimento de seu filho, pois não queria saber de nada quando estava bebendo.

Era uma pessoa violenta, envolvendo-se em muitas insanidades. Fumava maconha enquanto bebia. Com isso, deixava no bar todo o dinheiro que obtinha. Junto com a bebida, tomava também um antidepressivo, prescrito numa tentativa de tratamento com um psiquiatra. Tentou parar diversas vezes. Seu primeiro internamento aconteceu quando ele tinha 20 e poucos anos, por imposição de seu pai e de um tio. Não obteve êxito, pois não queria se tratar. A partir de então, seguiram-se mais de dez intervenções terapêuticas. Ele já conhecia a sala de AA, mas nunca tinha seguido o programa de tratamento. Quando se viu no fundo do poço, sem emprego, sem dinheiro para nada, fui pela dor procurar o AA. Estava em um processo de autodestruição.

\section{Comunidade terapêutica: Diana e Laura}

As "comunidades terapêuticas", regulamentadas pela Agência Nacional de Vigilância Sanitária e pela Secretaria Nacional de Políticas sobre Drogas, são sistemas estruturados com regras, limites claros e afetos controlados, através de responsabilidades, normas e horários (Sabino \& Cazenave, 2005). Elas constituem o contexto de opções que se oferece para atuar nessa especificidade. Na comunidade terapêutica Água da Vida, onde fiz a pesquisa, o "programa de tratamento" compreendia um período de seis meses de "internação", termo usado para se referir à residência das pessoas (chamadas de "residentes") no local. Nessa comunidade tive Diana e Laura como interlocutoras privilegiadas.

Diana narra que com 15 anos teve o primeiro contato com maconha no colégio: Nossa, eu me lembro como se fosse hoje, e aí eu não parei mais. Com 18 anos se casou, teve seu primeiro filho e ficou sete anos sem usar drogas. No entanto, continuava bebendo e fumando, e isso a levou a uma recaída anos depois. Um dia estacionou o carro em um bairro terrível da cidade e comprou 50 reais de cocaína, pois queria trabalhar mais para que a sua empresa crescesse. Seu marido descobriu, e os dois passaram a usar juntos, mesmo tendo casa, filhos e empresa para cuidar.

Mudam-se para uma praia do interior, procurando mudar de vida. Ela já havia entregado um carro para um traficante, estava negociando o segundo. A empresa tinha mais dívidas do que lucros, e seus filhos já estavam com a sua mãe. Um dia foi comprar cocaína e só tinha crack. O traficante lhe ensinou a fumar. Foram quatro meses de uso que me capacitaram a ser uma ameba. Seus pais descobriram e foram à praia trazê-la de volta, mas logo voltou a usar crack. Um dia, sua mãe, que vivia entrando furtivamente em sua casa por já estar desconfiada, encontrou Diana tendo uma overdose. Diana só acordou no hospital, sendo depois encaminhada a uma clínica psiquiátrica.

Laura, que também estava participando do programa de tratamento da comunidade, diz que começou a usar droga por brincadeira, em festas. Ela acha que quase todo mundo começa assim, no meio da festa, no meio da bagunça, com os amigos, com a galera do colégio. Nesse momento passou a beber, apesar de nunca ter gostado muito de álcool. Depois conheceu a maconha, uma experiencia tenebrosa, e a cocaína: Tudo de bom a cocaína. Ela sempre cheirava com o namorado, enquanto ele fumava crack, que ela considerava coisa de mendigo. Um dia, entretanto, tendo acabado a sua cocaína, ela resolveu experimentar um pouco da pedra: Nunca mais eu gastei meu dinheiro em cocaina, ia tudo pra pedra. As amigas que começaram a usar junto com Laura, hoje em dia são normais. Só Laura ficou, e, com isso, perdi o controle né, fui parar onde fui parar, agora que eu tô saindo. Laura passou por uma série de intervenções terapêuticas, tendo chegado a morar por seis meses em uma biqueira, local onde havia mais ou menos umas dez casas habitadas por pessoas que sobreviviam do tráfico de drogas.

\section{Igreja do Santo Daime e Lorenço}

A instituição que mais se diferenciava das já mencionadas é a Igreja do Santo Daime Céu da Nova Vida (ICNV). "Santo Daime" é uma expressão multivocal, podendo referir-se a um movimento religioso e ao nome dado à substância psicoativa na forma de bebida ingerida durante os rituais (De Rose, 2006). Essa bebida, conhecida pelo nome de ayahuasca, é produzida pela cocção de duas plantas oriundas da floresta amazônica: o cipó-jagube e a folha-rainha. "Esta bebida é considerada como um 'ser divino', dotado de personalidade própria e capaz de curar e de transmitir conhecimento" (De Rose, 2006, p.35, aspas simples da autora).

A ICNV, localizada em uma área residencial em meio urbano, ocupa uma casa bastante ampla, pintada de verde e com grandes letreiros. Seus coordenadores reconhe o trabalho específico que desenvolvem para a cura da dependência química como uma importante diferença entre essa igreja e outras que compartilham do uso da ayahuasca. Embora estivesse eventualmente aberta para que interessados - usuários de drogas ou não - participassem dos rituais religiosos, a ICNV tem a característica de ser centrada na "cura de dependentes químicos". 
Conforme os relatos, a ICNV se encontrava propositalmente no meio urbano para que os "dependentes" tivessem facilidade de acesso a ela. De acordo com um dos dirigentes, a igreja tinha a característica de realizar uma obra social "principalmente para aqueles dependentes que não podiam pagar clínicas e psicólogos". Os "trabalhos de cura" para usuários de drogas aconteciam uma vez por semana. Para participar, as pessoas deveriam passar por uma "triagem" basicamente questionamentos sobre a intenção que as levaram a buscar a igreja - com o padrinho, ou com Lorenço, um outro participante importante da igreja, cuja narrativa será apresentada a seguir.

Lorenço conta que começou a fumar maconha com 20 anos, no segundo ano da faculdade. Aos 23 anos, já formado, começou a usar cocaína, de pouquinho, de pouquinho... Nos últimos cinco anos de utilização da droga, torna-se um usuário contumaz. Lorenço acredita que o uso compulsivo de drogas está relacionado a alguma vergonha, a alguma coisa que a pessoa quer esconder, a algum trauma, a uma fuga. No seu caso, ele associa muito à relação com a sua mãe. Começou a se esconder um pouco na droga porque brigavam muito, sentia muita raiva dela. Depois, surgiram novos medos usando drogas. Fez muita bobagem, sente muita vergonha e está procurando entender isso no Santo Daime.

Ele decidiu parar, porque tinha um projeto de vida. Seu pai não estava bem, sua filha se interessava por drogas, as artérias do seu coração estavam entupidas por causa da cocaína, fumava três a quatro carteiras de cigarro por dia, bebia muita cerveja. Foi boêmio até os 40 anos, pois planejava aproveitar bastante a vida até essa idade; depois, queria se estabilizar e ter uma vida mais espiritualizada. Já estava parando aos poucos, mas tinha um amigo, também usuário de drogas, que havia se curado no Santo Daime. Então, através dessa mediação, ele também conseguiu se curar na ICNV. Desde então nunca mais usou drogas e permanece vinculado à igreja.

\section{Experiências de ruptura e o processo de institucionalização}

\section{Eventos críticos, agência de vigilância e redes sociais}

Chamo novamente Diana para reconstituir seu episódio de overdose. De acordo com ela, sua empresa tinha mais dívidas do que lucros e não conseguia mais cuidar das crianças que já estavam morando com seus pais. Para mudar de vida, ela e o marido se mudaram para a praia, onde abriram uma empresa: nossa, fazendo chover, vivendo uma ilusão daquelas. Diana conseguiu ficar sete meses sem usar drogas, mas uma noite, em um luau, cheirou novamente cocaína e recomeçou a destruição. Seus pais descobriram e a levaram de volta para sua cidade. Ficou dois meses separada do marido até que ele foi procurá-la. Decidiram montar uma casa: a ideia era de recomeçar. A ideia era de se matar né! Ficaram um mês sem fumar crack, até que seu marido recebeu o primeiro salário. Era segunda-feira, e Diana e seu marido fumavam desde a sexta.

Ele lhe disse que iria até a empresa dizer que ela não estava bem para voltar para casa e fumarem mais: $o$ combinado era que eu não fumaria até ele voltar, mas, mal ele tirou o carro da garagem, eu já estava agarrada na lata. Diana sempre botava a tranca na porta de casa, pois sua mãe tinha a chave e entrava repentinamente. Nesse dia, ela se esqueceu de por a tranca. Diana fumou, fumou, fumou, e não se lembrou de mais nada, até acordar no hospital com seu pai sentado no sofá ao seu lado: eu abri o olho e já fechei ligeiro! Ela tivera uma overdose, uma parada cardiorrespiratória. Do hospital foi direto para uma clínica psiquiátrica, onde ficou por 28 dias. Seus pais, irmãos e cunhados decidiram interná-la na CRAVI: eu não estava em condições de resolver nada.

Esse relato reconstitui um episódio bastante circunscrito, trazendo para a cena contextos e pessoas que desestruturam uma trajetória de uso de drogas, apresentando aspectos importantes envolvidos nos contornos de sua definição. Como podemos perceber, os atores da rede familiar detêm, em grande medida, o monopólio tanto da definição quanto da resolução desse episódio que decidi chamar de "eventos críticos". Contudo, no caso de Diana, e como veremos adiante, a atuação desses agentes não se restringe a esses eventos; eles "sinalizam" sua presença desde momentos anteriores, próximos ou distantes, configurando uma "agência de vigilância", a partir de pistas, por exemplo, como ausências, e por ficarem "sabendo" do uso de drogas enquanto ela vivia na praia.

Logo, nesse episódio vivido por Diana, podemos perceber como a categoria analítica "evento crítico" surge de modo indissociável do que nomeei "agência de vigilância", que é posta em curso nas redes sociais do sujeito - especialmente a rede familiar -, vigiando suas ações após a constatação concreta ou a desconfiança do uso de drogas. Dessa forma, a agência de vigilância se conecta aos eventos críticos na medida em que está diretamente vinculada à eclosão do evento crítico que surge como resposta a determinados comportamentos interpretados como inaceitáveis. A agência de vigilância também faz pressupor o desdobramento do evento crítico que envolve o acionamento de uma instituição terapêutica, como veremos também nos próximos eventos críticos narrados.

O primeiro internamento de Jaime também foi em decorrência do que é considerado neste trabalho 
como evento crítico. Ele havia chegado de madrugada e quebrado tudo em casa. Seu pai, então, chamou a polícia, que o prendeu. No dia seguinte, seu pai e seu tio o levaram à força para ser internado: $\mathrm{em} 1986$ ainda faziam internamento à força. Nesses eventos críticos narrados por Diana e Jaime, podemos sugerir que o sujeito sucumbe e põe em curso uma dinâmica de delegações. Essa dinâmica movimenta um jogo de agências que atua na definição do problema, respondendo ou não à delegação posta pelo sujeito. Em ambos os relatos há uma complexidade significativa quanto à definição de quem é "o senhor da ação" na condução da dinâmica que vai resultar nas passagens pelas instituições terapêuticas. São episódios tensos, marcados por ambiguidades e permeados por aspectos velados.

Outro evento crítico foi contado por Laura. $\mathrm{Na}$ sua casa moravam suas irmãs, sua mãe e ela, todas com vozes muito parecidas. Um dia, um traficante ligou para sua casa, pois um cheque que ela lhe dera fora devolvido pelo banco. Ele pediu para ela cobrir o cheque, sem saber que estava falando com sua irmã. Sua irmã se passou por ela e se fez de desentendida: mas que cheque é esse que eu não tô lembrando? E então ele entrega tudinho: daquela droga lá, que você pegou, 50 gramas. E, se você quiser, chegou bastante droga, tem um produto novo. Quando chegou do trabalho, estava feita a muvuca. Estavam presentes suas irmãs, seu irmão, uma amiga, o marido dela. Ela não entendeu nada: O primeiro internamento foi assim, uma coisa meio de família, porque eles entraram em pânico. Acredita que eles tinham até corda pra me amarrar? Ai eu fui porque senão ia ser aquele barraco. Levei meio na piada assim, até eu ver onde en fui parar.

Nesses relatos sobre os eventos críticos experienciados por Diana, Jaime e Laura, a dinâmica social movimentada pelo jogo de agências atua tanto na identificação e consequente interpretação quanto no controle dessas dinâmicas. Assim, são eventos que se realizam como perturbações físico-morais (Duarte, 1986), desde seus contornos iniciais, pois abarcam condições, eventos de vida ou situações consideradas irregulares ou anormais pelos atores sociais, afetando sua vida moral, sua autorrepresentação e seus sentimentos, muito além da sua imediata corporalidade (Duarte, 2003). Esses episódios não são vivenciados isoladamente, são processos que emergem e se delineiam pelo contato dialógico e reações dos outros, desde o momento em que se "detecta" o uso de drogas, próximo ou distante da emergência do evento crítico. Nesse sentido, as definições e reações dos outros são fundamentais para a constituição do papel de "sujeito da perturbação", demonstrando que elas se definem em um processo interativo que envolve a participação de vários atores pertencentes às redes sociais.

Apesar de os usos e de os usuários de drogas serem marcadamente heterogêneos entre si, todos têm em comum o fato de estarem envolvidos em uma prática ilegal. Por isso, podem ser incluídos na categoria de comportamento desviante e movimentam "sistemas de acusação" (Velho, 1974). A categoria de drogado tem sido acionada como categoria de acusação nas sociedades complexas, relacionada à ideia de doença mental, que explica o que não possui explicação e reifica visões de mundo (Velho, 1974). Essas categorias se confundem e implicam um ritual de exorcismo bastante elaborado, no qual participam um aparelho institucional que alcança a sua legitimação por intermédio de um "saber oficial" (Velho, 1974, p. 57), respaldado pela possibilidade da coerção e da lei, atuantes por intermédio de todo um aparato que esse saber mobiliza.

Nessa conjuntura, as pessoas das redes sociais integrantes dos processos narrados pelos interlocutores constituem agências de vigilância para controlar e procurar suprimir esses comportamentos tornados desviantes, denunciados pelos próprios sujeitos através da revelação de diferentes sinais. Os "sinalizadores" de uma perturbação que envolve o uso de drogas podem ser entendidos de várias maneiras: através de momentos circunscritos, que abrangem uma gama de sinais diferenciados, como, por exemplo, a denúncia involuntária realizada pelo traficante no relato de Laura e o rompante violento no espaço doméstico, no caso de Jaime; ou ainda podem ser considerados a partir da percepção de comportamentos anteriores, próximos ou distantes, como a vigilância da mãe de Diana.

Os eventos críticos, nesse contexto, portanto, são episódios dramáticos e de acentuada inflexão nas trajetórias dos sujeitos. Resultam em uma ruptura com a vida cotidiana e com a trajetória de uso de drogas, mesmo que essa interrupção do uso seja apenas momentânea. Não é possível determinar temporalmente (quando começaram e quando terminaram) esses eventos de forma rígida. No entanto, eles envolvem uma dinâmica sequencial na medida em que podemos compreender, com base nos episódios relatados, que seus contornos começam a se definir a partir da sinalização de uso de drogas feita pelos sujeitos e da subsequente interpretação (realizada por participantes das redes sociais dos sujeitos) desses sinais como indicadores desse uso.

Esses participantes passam então a contornar agências de vigilância, fundamentais para a emergência do evento crítico, pois é a partir desse agenciamento que os atores sociais vão determinar o que não é mais aceitável. Deflagra-se assim todo um processo de perturbação físico-moral que deposita a expectativa de seu regramento no acionamento de instituições terapêuticas. Os eventos críticos, portanto, se caracterizam por uma dinâmica processual e dramática e possuem como elementos atuantes fundamentais à presença de sinalizadores de uso de drogas: a agência de vigilância constituída em torno do comportamen- 
to desviante e o acionamento de alguma instituição terapêutica como promessa de resolução.

\section{Avaliação, moralidade e corporalidade}

Se os eventos críticos já analisados demonstram, por um lado, a entrega do sujeito às mãos de outros atores sociais, fundamentais nos agenciamentos que os conduzem a uma intervenção terapêutica, há, por outro lado, outra classe de relatos que não envolve eventos circunscritos e um explícito jogo de agências. Abrangem, por sua vez, percepções acerca de toda uma conjuntura consequente do uso de drogas, as quais levam a uma ruptura com a performance do sujeito na vida cotidiana e determinam a passagem para a instituição terapêutica, conforme veremos a seguir.

Jaime passou por mais de dez tratamentos. De acordo com a sua narrativa, começou a beber mais quando começou a trabalhar, porque na ocasião tinha dinheiro. Contudo, posteriormente, perdeu uma série de empregos por conta do alcoolismo. Só nos Correios, passou por cinco internamentos, até ser demitido. Depois foi admitido em um banco, de onde se demitiu porque, na sua insanidade, queria usar todo o fundo de garantia para beber. Nunca teve dificuldades de conseguir emprego, pois sempre manipulava nas entrevistas, mas nunca conseguia parar em emprego algum. Outro aspecto importante, consequente do alcoolismo para Jaime, se refere ao fim do seu casamento e à perda do contato com o filho. Esses elementos tomados em conjunto figuram como participantes para a avaliação do desejo de parar de beber. Diante dessas dificuldades, e por não ter dinheiro para mais nada, Jaime procura se tratar.

Por sua vez, Lorenço formula o discurso do trabalho de forma oposta a esse relato, o que evidencia a dificuldade com essa esfera por conta das drogas. Para o interlocutor, foi difícil trabalhar quando ficou sem utilizá-las. De acordo com sua explicação, o uso e o efeito da cocaína estavam vinculados ao seu trabalho de engenheiro com projetos que necessitam de um cálculo estrutural. Ficou uns dois meses sem conseguir trabalhar: talvez a maior dificuldade desta readaptação da vida sem drogas foi voltar a trabalhar sem utilizar drogas. Hoje em dia fica meio inconcebivel trabalhar utilizando drogas. Além disso, sua esposa sempre o acompanhou em todos os momentos da sua vida. Quando eu lhe pergunto: ela usava com você? Ele me responde: Não posso falar de uma pessoa que não está presente. Apenas digo que ela sempre me acompanhou.

Ou seja, o vínculo que Lorenço estabelece para a sua interrupção de uso de drogas não se refere ao rompimento que Jaime mencionou. Lorenço apresentou uma história bastante peculiar, de alguém que não se considerou no tão mencionado "fundo do poço" para decidir parar de usar, apesar do uso intenso nos últimos anos anteriores à interrupção. Lorenço decidiu parar por um projeto de vida. No seu entendimento, um engenheiro trabalha muito com projetos, metas para um ou dois anos, estruturalmente. Então ele tinha um projeto de parar de usar drogas aos 40 anos, que seria o ponto médio da vida: dizem que a gente nasce aos 40, né! Até os 40 ele tinha decidido viver uma vida mais boêmia, para depois procurar viver uma vida mais espiritualizada, com maior amadurecimento. Dessa forma, ao marcar não apenas o não rompimento com as esferas mencionadas, mas também seu domínio sobre as experiências e a condução da sua própria vida, seu relato se distancia dos demais.

Retornando a Jaime, sua avaliação crítica também aparece relacionada a um reconhecimento de um distanciamento de um padrão, que lhe causa dor, culpa e vergonha. Ele também estava com o orgulho ferido, sentia muita vergonha. Estava com trinta e poucos anos e não conseguia se manter em nenhum emprego, precisando pedir dinheiro à família para pegar o ônibus. Em suas palavras, estava em um processo de autodestruição, e, assim, a dor o levou a buscar o AA. Portanto, o rompimento dos vínculos com a família e com o trabalho não deve ser entendido isoladamente, pois, relacionado ao olhar sobre esses setores, aparecem a vergonha e a culpa. Esses sentimentos emergem a partir de uma autoavaliação em relação a um parâmetro dado socialmente, interpretado pelo sujeito.

A perturbação, na medida em que se constrói a partir de um desvio, se confunde com o "impuro", contradizendo classificações valorizadas (Douglas, 1976). Nesses relatos, a lógica que a informa é a lógica da poluição, do deslocado, do anômalo na percepção de si mesmo ou dos outros. A doença ultrapassa o limite intrapessoal e físico, afeta as relações sociais e contamina a relação do sujeito com o mundo (Campos, 2003). O usuário de drogas atua como um agente contagioso, ${ }^{4}$ especialmente nas esferas do trabalho e da família; quando identificado por si mesmo e/ou pelos outros, aciona um processo elaborado de exorcismo (Velho, 1974).

Os "sinalizadores" da perturbação, portanto, representam uma gama de elementos que agem conjuntamente na determinação dos processos de passagem. O próprio uso de drogas - como comportamento desviante e, portanto, moralmente condenável - atua como um fator que demarca a constituição de uma experiência de perturbação. Contudo, esse fator des-

4. Não é nova a ideia de considerar uma dimensão representacional do "contágio" nos estudos sobre usos de drogas. Sobre uma discussão acerca de uma "teoria cultural do contágio" também distante das acepções biomédicas, ver o trabalho de Fainzang (1996) no qual Campos se inspira. 
viante que envolve o uso ilícito de drogas não deve ser compreendido como uma prática reduzida em si mesma. Isto é, devemos também levar em conta o contágio nos vínculos sociais, especialmente nos vínculos de trabalho e nos vínculos familiares, como elemento importante que opera na deflagração dos eventos críticos e na percepção de uma conjuntura de vida insustentável. Portanto, toda uma dinâmica social está incluída no contágio que define a leitura da perturbação.

De acordo com Duarte (2003), há sempre uma dimensão corporal envolvida nessa definição, razão pela qual não é possível desconsiderá-la. Com efeito, os sinalizadores podem ser de outra ordem da experiência e da percepção corporal. Jaime comenta: Estou hoje com 65 quilos e eu tava com 59 quilos, aparência bem mais envelhecida, né [...] Higiene não se faz nenhuma, né [...]. Ah, é um farrapo humano, né. Por isso o tratamento é bom, a pessoa se recupera rápido. Lorenço também parte de uma observação que revela sua percepção corporal: Fumava demais, de três a quatro carteiras de cigarro por dia, muita cocaína e muita cerveja, barbaridade de cerveja, e, com isso, o coração deteriorou, né. Entupiram-se as artérias, estava para fazer um cateter [cateterismo], mas com a parada imediata do cigarro, do álcool e das drogas, consegui contornar e não fiz o cateter. Não foi necessário.

Com base nesses relatos, evidencia-se a leitura do próprio corpo a partir da sua decadência balizada por um olhar sobre a magreza e a debilidade como indicadores de um problema gerado pelo uso e dos cuidados que se tem ou se deve ter com ele. Contudo, podemos compreender que o corpo não entra no jogo de avaliações apenas a partir de uma leitura que dele pode ser feita. Podemos perceber conjuntamente uma leitura corporificada da situação, através da qual largamente nos movemos (Rabelo, 2005) e, assim, o limite da vida com o uso de drogas pode se emergir corporalmente. O corpo, nesse caso, se apresenta como uma experiência que sintetiza afetos, habitus, afeições, como discute Csordas (1990) no conceito de embodiment. Para o autor, o corpo é tomado como sujeito (subject) da cultura, e não como objeto (object).

Dessa forma, a corporalidade é sentido e veículo da experiência (Maluf, 2002). Diana se considerava fisicamente horrível quando entrou em tratamento, pesando 49 quilos. Enquanto sentido e enquanto veículo, a corporalidade pode sinalizar um acúmulo de experiências moralmente condenáveis a si mesmo, bem como um limite dado corporalmente às situações. É assim um corpo fabricado, paradoxalmente, a partir da sua decadência. O corpo também atua como uma agência de expressão ao outro, e não apenas como um elemento que salta à percepção de si mesmo. Assim, se a fala do corpo é a expressão de uma autopercepção, tanto enquanto representação quanto uma autopercepção corporificada de uma conjuntura emergida no engajamento com o uso de drogas, a re- ferência ao corpo que fala aos outros é a expressão da leitura de uma autopercepção. Dessa forma, a corporalidade, segundo Csordas (1990), também pode ser tomada como um objeto de representação, ou seja, como um corpo que pode ser lido como texto.

Considerando a locução físico-moral em um continuum, a conjuntura de vida e os eventos críticos tomados conjuntamente evidenciam um acentuado deslocamento para o polo da moralidade. Esses elementos tomados de forma intrincada podem ser condensados em uma lógica de "poluição", nos termos de Douglas (1976), constituindo um conjunto de "sintomas morais". Assim, na medida em que as perturbações em que se envolvem os usuários de drogas são matizadas por "sintomas morais", a leitura e mediação desses episódios se dão por uma lógica particular que não coincide com a leitura sintomatológica oficial da biomedicina. Entretanto, se há um jogo de agências e toda uma leitura social que tornam os sintomas "morais", não é possível ignorar a qualidade das experiências subjetivas, tampouco esvaziar o quanto pode haver de sofrimento nessas experiências. Como indica Jaime: isso eu estou contando naturalmente né, mas imagina a minha angústia! As pessoas contavam-me histórias sobre importantes momentos de suas vidas que traziam consigo, muitas vezes, expressões de sofrimento e de episódios tensos.

Se a experiência da perturbação interpela a totalidade da pessoa (Duarte, 2003), alcançando seu "limite mais restrito", enquanto experiência de fragmentação da sua unidade, também é ponto de partida para sua reconstrução (Duarte, 1986). Portanto, por um lado, essas experiências são potencialmente fragmentadoras da pessoa, e, por outro, ao ser o acionamento de uma instituição terapêutica, a alternativa que lhes cabe - embora os sujeitos envolvidos não tenham, necessariamente, um conhecimento sobre o que representam e como são agenciadas - já define o contorno que será o guia para a reconstituição. Nesse sentido, o que está em jogo é o próprio estatuto do sujeito, a partir da possibilidade de reconstrução.

A leitura dos "sintomas morais" e a consequente deflagração das rupturas são processos delimitados pelo que podemos compreender como a emergência de conflitos sociais, entre os sujeitos e os seus laços sociais, e entre expectativas diferentes dos próprios sujeitos, na medida em que eles se avaliam em relação a esses momentos inflexivos. A partir desses conflitos, a condução da pessoa é no sentido de uma "transformação", de uma "metamorfose", que vai se viabilizar, com maior ou menor sucesso, através do acionamento de uma instituição terapêutica. Nesse sentido, o horizonte das estratégias de elaboração das perturbações, iniciadas através da leitura dos sintomas morais, é a transformação do sujeito - processo que deve transcorrer nas instituições acionadas. 


\section{(Re)elaboração da experiência e localização do sujeito}

Se, por um lado, o horizonte das estratégias de elaboração das perturbações é a transformação do sujeito, por outro, precisamos considerar que as próprias narrativas que analisamos neste trabalho são expressões dessa transformação. Apesar das diferenças existentes entre as instituições terapêuticas nas quais os sujeitos estavam inseridos, é importante mencionar que elas possuíam representações centrais que as aproximavam consideravelmente. Toda a trama narrativa dos sujeitos se dava em torno da noção de dependência química que circulava nos contextos institucionais. Nesse sentido, a apropriação desse entendimento por parte dos sujeitos lhes fornecia uma versão explicativo-causal dos eventos de ruptura que emergiam em suas trajetórias. Dessa forma, as instituições lhes oferecem um significado, e as vivências nelas thes oferecem caminhos para o acesso a esse mesmo significado.

A localização do sujeito em uma ou outra instituição é menos importante do que o fato de ele estar inserido em uma rede absenteísta que opera em grande medida com o discurso biomédico da dependência química. De fato, a escolha subjetiva do sujeito ou de suas redes de relações por uma ou outra instituição não era relatada como resultado de uma escolha espontânea e criteriosa por determinado local de tratamento devido a características específicas que esse local poderia possuir. A escolha se centrava principalmente na expectativa de intervenção no uso e interdição desse mesmo uso que as terapêuticas prometiam fazer. Também é importante notar que alguns dos sujeitos haviam passado por mais de uma terapêutica e não falavam necessariamente de uma forma direta a partir do espaço institucional em que se encontravam por ocasião da pesquisa.

Precisamos, portanto, trabalhar com o segundo significado da categoria "perturbação" já definida anteriormente. Essa categoria aparece ressignificada pela categoria de "doença", mais especificamente, "doença da dependência química", representação partilhada pelas instituições terapêuticas. Nesse sentido, tornam-se menos visíveis as fronteiras entre a CRAVI, a ICNV e o AA. Essas instituições atuam como agenciamentos terapêuticos, agenciando a construção de identidades a partir das representações sociais vigentes em torno do "fenômeno das drogas". Essa similaridade em concepções centrais implica um entrecruzamento com as representações definidas pelo monopólio da interpretação biomédica, que define a noção de dependência de drogas e a insere no amplo espectro das doenças mentais. Essas doenças são determinadas por uma epistemologia fisicalista, não possuem "cura" e, assim, estão sempre dispostas à "recidiva" e à "progressão".

O que em nossa sociedade chamamos de doença é uma construção sociocultural e subjetiva, e, assim, não pode ser reduzida a manifestações biológicas (Langdon, 2003). Ou seja, categorias como "saúde" e "doença" são relacionais e devem ser desnaturalizadas. Assim, experiências que compõem as trajetórias de vida são reinterpretadas através da noção de doença que é mais densamente compartilhada nas instituições terapêuticas, em um esforço geral de conhecimento - "identificar" sintomas e decodificar sua articulação específica como "doença”. Nessa direção, a prática da abstinência está vinculada a um código específico da "doença da dependência química". A abstinência pode ser compreendida como um sistema simbólico atuante como organizador da existência e de um modo de vida (Campos, 2003). A partir da "cultura da abstinência", os contextos terapêuticos jogam não apenas com a noção da "doença da dependência química" como "incurável, progressiva e fatal", mas, principalmente, com o "ser" dependente químico.

É interessante notar que os contextos terapêuticos faziam seus arranjos locais de sentido a partir do discurso biomédico mais amplo. Por exemplo, a distinção entre o uso e o abuso de drogas realizada por esse discurso e já apropriada pelo senso comum não encontra reverberação densa nas narrativas dos sujeitos. Ou, ainda, são noções reformuladas na trama dos discursos nativos que constroem o ser dependente químico. A fronteira entre uso e abuso é extremamente tênue e não encontra relevância significativa nesse discurso, pois o que é importante é a (re)constituição de si mesmo enquanto dependente químico. $\mathrm{E}$, nessa direção, uso e abuso são categorias idênticas que se separam apenas na trajetória cronológica de determinados sujeitos.

Apesar de existir o reconhecimento de que foi a partir do abuso de drogas que se estabeleceu significativamente a perturbação na trajetória (como fica evidente na fala de Lorenço quando explica que nos últimos anos de relacionamento com as drogas intensificou o uso), essa distinção parece se desfazer quando há um reconhecimento de si mesmo como dependente químico. De fato, havia um aspecto comum nas narrativas que se esforçava por explicar como desde o primeiro uso já se configura um abuso. O dependente químico é aquele sujeito que não sabe estabelecer um uso moderado e não é capaz de exercer um controle sobre esse uso. Portanto, a dependência química está contida em uma determinada forma de se relacionar com as drogas e até com o mundo de um modo geral. O que está em jogo é uma determinada qualidade da relação com o mundo e não critérios quantitativos de uso de drogas. 
Como podemos perceber, as instituições com as quais trabalhamos podem ser percebidas como articuladoras das experiências e produtoras de sentido para as perturbações que envolvem o uso de drogas. Segundo Figueira (1976), os recursos socialmente disponíveis aos sujeitos que atravessam períodos críticos da vida são capazes de fornecer, em momentos de crise ou doença, uma versão do acontecimento. Dessa forma, um sistema fornece ao sujeito uma perspectiva coerente para a apreensão subjetiva da sua trajetória pessoal, propiciando um parâmetro identitário. As representações institucionais que incidem sobre os sujeitos durante suas vivências nas instituições podem ser agenciadas de forma a dar sentido aos "eventos críticos" e às "conjunturas de vida", traduzidos em algumas falas pela experiência do "fundo do poço", modelando uma compreensão de si mesmo através da noção de dependência química.

\section{Considerações finais}

Como vimos, as experiências desencadeadoras de intervenção terapêutica foram desdobradas em duas categorias: os eventos críticos e as conjunturas de vida. A primeira é caracterizada por dinâmicas de delegações que envolvem as redes sociais, acionadas através de sinalizadores. São dramas sociais que eclodem com a descoberta do uso de drogas por parte dos familiares ou pela configuração de experiências de violência contra os outros ou si mesmo, que apontam a institucionalização como única saída, acionadas pelas redes sociais dos sujeitos e não diretamente por eles próprios.

A segunda traz a avaliação dos sujeitos sobre as suas vidas na época em que atualizavam o uso de drogas e/ou nos períodos anteriores à institucionalização. Família e trabalho foram mencionados do ponto de vista da percepção de práticas de descuido, de negligência e de ruptura com essas esferas sociais, indicando uma classe de sintomas morais ligados ao social e não ao aspecto biológico. Contudo, as leituras e experiências corporais foram centrais na avaliação desses momentos. Essas percepções demonstram o reconhecimento de um problema de uso de drogas e a incapacidade de geri-lo sem o auxílio de um recurso terapêutico. A institucionalização é narrada como consequência de uma escolha diretamente realizada pelos sujeitos.

Se as narrativas dos sujeitos nos permitem compreender, por um lado, aspectos e elementos que atuam nas definições de experiências de perturbação dos usuários de drogas que os conduzem a instituições terapêuticas, por outro, elas nos permitem também compreender o papel das instituições no ordenamento sociocultural do fenômeno das drogas. Essas instituições oferecem um parâmetro identitário e põem em curso processos de articulação da experiência através das representações sociais da medicalização do uso de drogas, contornando um sujeito dependente químico, reelaborando experiências singulares de modo a configurá-las como modelos coletivos.

Portanto, tanto eventos críticos quanto circunstâncias de vida são ao mesmo tempo causa e produto das experiências vivenciadas nas instituições terapêuticas. Essas duas dimensões dos relatos só podem ser separadas analiticamente, pois ambas são expressões dos processos narrativos que reconstituíam as experiências no momento da entrevista. O modo de narração e os conteúdos narrados indicam algumas das consequências importantes na vida de usuários de drogas: da experiência da institucionalização e, dessa forma, da construção sociocultural dominante do fenômeno.

\section{Referências}

ABU-LUGHOD, Lila. Writing against culture. In: FOX, Richard (Org.). Recapturing anthropology: working in the present. Santa Fe: School of American Research Press, 1991. p.137-162.

CAMPOS, Edemilson Antunes de. Alcoolismo, doença e pessoa em uma associação de ex-bebedores: o caso dos Alcoólicos Anônimos. In: REUNIÃO DE ANTROPOLOGIA DO MERCOSUL: Antropologia em perspectivas, 5. Florianópolis - SC, 2003.

CARNEIRO, Henrique. Transformações do significado da palavra droga: das especiarias coloniais ao proibicionismo contemporâneo. In: CARNEIRO, Henrique; VE-
NÂNCIO, Renato Pinto (Org.). Álcool e drogas na história do Brasil. São Paulo: Alameda; Belo Horizonte: Editora PUCMinas, 2005. p.11-28.

CSORDAS, Thomas. Embodiment as a paradigm for Anthropology. Ethos, v. 18, n. 1, p. 5-47, 1990.

DE ROSE, Isabel Santana. Repensando as fronteiras entre espiritualidade e terapia: reflexões sobre a cura no Santo Daime. Campos, Curitiba, v. 17, n.1, p. 35-52, 2006.

DOUGLAS, Mary. Pureza e perigo. São Paulo: Perspectiva, 1976.

DUARTE, Luiz Fernando Dias. Da vida nervosa nas classes trabalhadoras urbanas. Rio de Janeiro: Zahar/CNPQ, 1986. 
DUARTE, Luiz Fernando Dias. Indivíduo e pessoa na experiência da saúde e da doença. Ciência E Saúde Coletiva, Rio de Janeiro, v. 8, n. 1, p. 173-184, 2003.

FAINZANG, Sylvie. Ethnologie des anciens alcooliques: la liberté ou la mort, Paris: PUF, 1996.

FIGUEIRA, Sérvulo Augusto. Notas introdutórias ao estudo das terapêuticas: Lévi-Strauss e Peter Berger. In:

Sociedade e doença mental. Rio de Janeiro: Campus, 1976. p. 87-148.

LANGDON, Esther Jean. Cultura e os processos de saúde e doença. In: SEMINÁRIO CULTURA, SAÚDE E DOENÇA. Anais..., Londrina: MS-UEL-SMAS/PML, 2003. p.91-107.

MALUF, Sonia Weidner. Corporalidade e desejo: tudo sobre minha mãe e o gênero na margem. Revista de Estudos Feministas, Florianópolis, v. 10, n. 1, p.143-153, 2002.

RABELO, Miriam Cristina Marcilio. Religião e a transformação da experiência: notas sobre o estudo das práticas terapêuticas nos espaços religiosos. Ilha: Revista de Antro- pologia, Florianópolis, v. 7, n. 2, p. 125-145, jul./dez. 2005. SABINO, Nathalí di Martino; CAZENAVE, Sílvia de Oliveira Santos. Comunidades terapêuticas como forma de tratamento para a dependência de substâncias psicoativas. Estudos de Psicologia I, Campinas, v. 22, n. 2, p. 157174, abr/jun, 2005.

SCHNEIDER, Jacqueline; GROISMAN, Alberto. Pesquisa qualitativa, saúde e uso de drogas: desdobramentos e implicações da utilização da técnica da entrevista de fala aberta. Florianópolis: Universidade Federal de Santa Catarina, 2011. Manuscrito.

VARGAS, Eduardo Viana. Entre a extensão e a intensidade: corporalidade, subjetivação e uso de drogas. Tese (Doutorado) - Pós-Graduação em Sociologia e Política, Universidade Federal de Minas Gerais, Belo Horizonte, 2001. VELHO, Gilberto. Desvio e divergência: uma crítica da patologia social. Rio de Janeiro: Zahar, 1974.

ZALUAR, Alba. Integração perversa: pobreza e tráfico de drogas. Rio de Janeiro: Editora FGV, 2004.

\title{
Drug users rupture experiences
}

\begin{abstract}
This work discusses drug users trigger narrative experiences of therapeutic intervention based on ethnography realized on the following institutions located on the metropolitan region of Curitiba, State of Paraná, Brazil: Church of the Santo Daime Céu da Nova Vida, Therapeutic Community Água da Vida and an Alcoholics Anonymous group. Through reconstruction and interpretation of the narratives, I mark acting elements in the process of definition of ruptures in the paths of life, articulated in the analytical categories emergency of critical events and circumstances of life. From the reading of these categories, I suggest the constitution of the physical-moral disturbance on the participants trajectory. As a joint perspective, I suggest also that the stories demonstrate the formulation of collective models of evaluation and reformulation of the experiences, given by the abstentistic logics of drug use.
\end{abstract}

Key words: drug; experience; trajectory; rupture; disturbance.

\section{Experiencias de ruptura en usuarios de drogas}

\section{Resumen}

Este trabajo discute narrativas de usuarios de drogas sobre experiencias desencadenantes de intervención terapéutica a partir de etnografía realizada en las siguientes instituciones ubicadas en la región metropolitana de Curitiba, estado de Paraná, Brasil: Iglesia de Santo Daime Céu da Nova Vida, comunidad terapéutica Agua Da Vida y un grupo de Alcohólicos Anónimos. Por intermedio de la reconstrucción e interpretación de las narrativas, indico elementos actuantes en el proceso de definición de rupturas en las trayectorias de vida, articulados en las categorías analíticas emergencia de eventos críticos y coyuntura de vida. A partir de la lectura de estas categorías, sugiero la constitución de perturbación físico-moral en la trayectoria de los interlocutores. Como una perspectiva conjunta, sugiero también que los relatos demuestran la formulación de modelos colectivos de evaluación y reelaboración de las experiencias, pautados por la lógica ausentista y medicalizadora del uso de drogas.

Palabras clave: drogas; experiencia; trayectoria; ruptura; perturbación. 